\title{
FERTILIDADE DO SOLO E NUTRIÇÃO DA MANGUEIRA 'UBÁ' EM CONSÓRCIO COM BRAQUIÁRIA E SOB ADUBAÇÃO MINERAL, ORGÂNICA E ORGANOMINERAL ${ }^{1}$
}

\author{
Anália Lúcia Vieira Pacheco², Karina Schulz Borges ${ }^{3}$, Gilberto Bernardo de Freitas ${ }^{4}$, Gerival Vieira ${ }^{4}$
}

\begin{abstract}
RESUMO - Devido ao clima apropriado ao cultivo da mangueira, a Zona da Mata mineira destaca-se pela produção de manga 'Ubá', contudo, a maior parte dos pomares é conduzida praticamente sem nenhum tipo de trato cultural, inclusive adubações e práticas de conservação do solo. Assim, o objetivo deste trabalho foi avaliar a fertilidade do solo e a nutrição da mangueira 'Ubá' após seis anos de cultivo com adubações mineral, orgânica e organomineral. Visando a proteção do solo e a ciclagem de nutrientes foi semeada Brachiaria brizantha nas entrelinhas do pomar, por ocasião do plantio das mangueiras. Utilizou-se cama de frango como adubo orgânico. O experimento iniciou em 2007, com quatro tratamentos: controle (apenas adubação de plantio), adubação mineral indicada para a cultura, adubação orgânica equivalente à adubação mineral e adubação organomineral (metade da dose da adubação mineral e metade da orgânica). Antes da implantação do pomar foi feita uma análise de solo da área experimental e ao término do experimento foram realizadas análises de solo e tecidos foliares. Adubações orgânicas proporcionaram maiores efeitos residuais de fósforo, potássio e magnésio no solo que adubações minerais e organominerais. O manejo da braquiária nas entrelinhas do pomar, através de roçadas periódicas, resultou em um aumento expressivo no teor de matéria orgânica do solo, além de propiciar a ciclagem de nutrientes. A adubação organomineral proporcionou uma nutrição mais equilibrada para as plantas.
\end{abstract}

Palavras chave: Brachiaria brizhanta, cama de frango, cultivo de sequeiro, Mangifera indica L.

\section{SOIL FERTILITY AND MANGO 'UBÁ' NUTRITION IN CONSORTIUM WITH BRACHIARIA UNDER MINERAL, ORGANIC AND ORGANOMINERAL FERTILIZER}

\begin{abstract}
Due to the appropriate climate for the cultivation of the hose, the Zona da Mata mineira stands out for mango production 'Ubá', however, most of the orchards are conducted practically without any cultural tract, including fertilizer and soil conservation practices. The objective of this work was to evaluate soil fertility and nutrition 'Ubá' hose after six years of cultivation with mineral fertilizer, organic and organic. Aiming to protect the soil and nutrient cycling was seeded Brachiaria brizantha in the orchard lines, at planting hoses. We were used poultry litter as organic fertilizer. The experiment began in 2007, with four treatments: control (only planting fertilization), mineral fertilizer suitable for cultivation, organic fertilizer equivalent to mineral fertilizer and organic fertilizer (half of the mineral fertilizer dose and half organic). Before the orchard deployment was made a soil analysis of the experimental area and the end of experiment soil samples were collected and leaf tissues. Organic phosphorus fertilization gave higher residual effects, potassium and magnesium in the soil minerals and organomineral fertilizer. The management of Brachiaria in the orchard lines through periodic mowing resulted in a significant increase in the content of soil organic matter, as well as providing nutrient cycling. The organic-fertilizer provided more balanced plant nutrition.
\end{abstract}

Keywords: Brachiaria brhizanta, Mangifera indica L., poultry litter, rain-fed cultivation.

\footnotetext{
${ }^{1}$ Parte da dissertação de Mestrado em Fitotecnia, UFV, do segundo autor.

${ }^{2}$ Engenheira-Agrônoma, Doutoranda. Departamento de Fitotecnia, Universidade Federal de Viçosa, Avenida Peter Henry Rolfs, s/n, 36570-000, Viçosa, Minas Gerais, Brasil. (31) 3899-1326. analia.pacheco@ufv.br (autora para correspondência).

${ }^{3}$ Biológa, Doutoranda. Departamento de Agricultura, Universidade Federal de Lavras, Campus Universitário, Caixa Posta 3037, 37200-000, Lavras, Minas Gerais, Brasil. karina.schulz.borges@gmail.com

${ }^{4}$ Engenheiros-Agrônomos, DS. Departamento de Fitotecnia, Universidade Federal de Viçosa, Av. Peter Henry Rolfs, s/n, 36.570-000 - Viçosa, Minas Gerais, Brasil.gerival@ufv.br, bernardo@ufv.br
} 


\section{INTRODUÇÃO}

Com o declínio da cultura da cana-de-açúcar na região da Zona da Mata mineira, na década de 90 do século passado, vários municípios da região começaram a desenvolver programas de incentivo à fruticultura, o que resultou na implantação de uma área significativa de pomares de manga, goiaba, maracujá, coco, banana, dentre outras fruteiras. As frutas produzidas são comercializadas em mercados locais e regionais de frutas in natura e também junto às indústrias de polpas, sucos e doces de frutas que se estabeleceram na região. Dentre estas destaca-se o cultivo da manga variedade 'Ubá', cuja polpa possui características de cor, sabor e textura adequadas ao processamento para produção de néctar, sucos e geleias, sendo, portanto, preferida pelas agroindústrias.

Na região da Zona da Mata mineira, na cidade de Guidoval foram produzidas $9 \mathrm{t} \mathrm{ha}^{-1}$; em Guiricema foram 8 t ha $^{-1}$ e em Visconde do Rio Branco alcançou a produção $6 \mathrm{t} \mathrm{ha}^{-1}$ de manga (IBGE, 2010). Apesar da expressiva produção de manga 'Ubá' na Zona da Mata mineira, a produtividade média dos pomares em nível regional é baixa, ficando inferior à produtividade média nacional de $13 \mathrm{t} \mathrm{ha}^{-1}$ (MAPA, 2012). Essa diferença entre a produtividade média regional e nacional pode ser explicada pela inadequada nutrição das plantas cultivadas na região. A maior parte da produção de manga 'Ubá' da Zona da Mata é proveniente de agricultores familiares, que tem na mangicultura uma importante fonte de renda. Em 2009, parte desses agricultores aderiu voluntariamente ao sistema orgânico de produção de manga proposto por uma agroindústria regional e atualmente, a região é produtora de polpa de manga 'Ubá' convencional e orgânica, comercializada nos mercados nacional e internacional. Estes dois sistemas de produção (convencional e orgânico) necessitam de distintos sistemas de adubação de plantas, uma vez que na agricultura orgânica é proibido o uso de adubos minerais de alta solubilização (Ramos et al., 2009). A qualidade das frutas orgânicas e convencionais ofertadas a uma agroindústria da Zona da Mata mineira varia em função de diversos fatores, inclusive da adubação, entretanto, produtores orgânicos ofertaram frutas de melhor qualidade que os convencionais (Pacheco et al., 2015). Existem poucos dados na literatura sobre a resposta de mangueira a adubações orgânicas, principalmente no sistema de cultivo de sequeiro praticado nas condições edafoclimáticas da Zona da Mata mineira.

A utilização de cama de frango na adubação orgânica de plantas constitui importante iniciativa, uma vez que na região são produzidas cerca de 300 toneladas por dia de cama de frango pelos avicultores integrados a uma indústria de alimentos instalada no município de Visconde do Rio Branco-MG. Este subproduto da criação de frangos de corte apresenta excelentes características nutricionais, podendo ser utilizado com sucesso na adubação das plantas. $\mathrm{O}$ aproveitamento de resíduos agrícolas na adubação de plantas, além de permitir um adequado destino aos resíduos (proteção do meio ambiente), melhora as características físico-químicas e biológicas do solo e em muitos casos permite uma redução no custo de produção da fruta (Borges et al., 2003). No Triângulo Mineiro também se observa uma grande produção de cama de frango e a busca por parâmetros para utilização deste resíduo como adubo orgânico. No capim Brachiaria decumbens, a aplicação de cama de frango aumentou a produtividade e os teores de P, K e Zn (Lana et al., 2010).

O sistema orgânico de produção de manga Ubá na Zona da Mata mineira apresenta elevado potencial devido às condições edafoclimáticas regionais serem adequadas ao cultivo da mangueira e também devido à crescente demanda mundial por produtos saudáveis e ecologicamente sustentáveis. Desta forma, estudos visando o estabelecimento de sistemas eficientes de adubação da mangueira 'Ubá' são necessários para aumentar ainda mais a competitividade da mangicultura regional, melhorando a produtividade dos pomares e a qualidade dos frutos produzidos.

Assim sendo, o objetivo deste trabalho foi avaliar a fertilidade do solo e a nutrição da mangueira 'Ubá' após seis anos de cultivo com adubações mineral, orgânica e organomineral e manejo de braquiária nas entrelinhas do pomar.

\section{MATERIAL E MÉTODOS}

O experimento foi conduzido na Fazenda Experimental da Sementeira, localizada em Visconde do Rio Branco, Minas Gerais (latitude de $21^{\circ} 00^{\prime} 37^{\prime}$ 'S, longitude de 42 50’26"O, altitude de 352 m). Segundo a classificação de Köppen, o clima da região é do tipo Aw (tropical chuvoso de savana) e caracteriza-se pela temperatura 
média anual de $21^{\circ} \mathrm{C}$, precipitação média de $1270 \mathrm{~mm}$ e umidade relativa de $80 \%$.

O pomar foi implantado em 2007, com o plantio de mudas enxertadas de mangueira 'Ubá' sobre 'Ubá', em uma área de baixada, no espaçamento de 10 x 10 $\mathrm{m}$. O solo da área experimental é classificado como Latossolo Vermelho Amarelo (Santos et al., 2013) apresentava, por ocasião da implantação do pomar, na camada de $0-20 \mathrm{~cm}$, as características indicadas na Tabela 1.

Em toda a área do pomar, após o plantio das mudas, foi aplicado, a lanço (superficialmente), calcário dolomítico, na dose de $1200 \mathrm{~kg} \mathrm{ha}^{-1}$, e, em seguida, semeada Brachiaria brhizanta nas entrelinhas do pomar. Nos dois primeiros anos de cultivo (2008 e 2009), todos os frutos emitidos pelas mangueiras foram eliminados a fim de permitir um adequado crescimento vegetativo das plantas. Foram realizadas podas anuais de limpeza e abertura de copa, além do controle das plantas espontâneas (Ramos et al., 2009). A braquiária foi manejada através de roçadas periódicas nas entrelinhas e capinas manuais próximo das mangueiras. O pomar foi conduzido sem irrigação (cultivo de sequeiro) e sem pulverização de produtos fitossanitários, de forma a representar o manejo adotado pelos mangicultores familiares da região. Foram aplicadas quatro adubações: 1) controle (apenas adubação de plantio), 2) adubação mineral indicada para a cultura (MIN), 3) adubação orgânica equivalente à adubação mineral (ORG), e 4) adubação organomineral com metade da dose de adubação mineral e metade da dose orgânica (ORGM).

As plantas do tratamento controle receberam apenas a adubação de plantio com 20 litros de composto orgânico (2,09\% N; 0,88\% P; 1,20\% K; 1,38\% Ca; 0,38\% Mg; 0,61\% S; 134,0 mg/kg Zn; 25781,0 mg/kg Fe; 615,0 mg/ kg Mn; 41,0 mg/kg Cu; 14,7 mg/kg B) + 400 g de superfosfato simples na ocasião de enchimento das covas.

As adubações minerais foram realizadas segundo a recomendação do Boletim Técnico 100 do IAC (Quaggio et al., 1997). Nas adubações orgânica e organomineral, foram utilizados como adubo orgânico a cama de frango (2,92\% N; 0,73\% P; 2,75\% K; 3,06\% Ca; 0,99\% Mg; 0,57\% S; 372,0 mg/kg Zn; 8722,0 mg/kg Fe; 707,0 mg/ $\mathrm{kg} \mathrm{Mn;} 64,8 \mathrm{mg} / \mathrm{kg} \mathrm{Cu} ; 61,9 \mathrm{mg} / \mathrm{kg} \mathrm{B}$ ) e cinzas provenientes da queima de eucalipto (4,78\% K; $1,58 \%$ P; $29,44 \%$ Ca e $1,82 \% \mathrm{Mg})$. Adubações de plantio, formação e produção foram feitas de acordo com a descrição das Tabelas 2, 3 e 4.

Ao término do experimento, foram realizadas análises do solo da área experimental e de tecidos foliares das mangueiras 'Ubá'. As amostragens de solo foram realizadas nas profundidades de $0-20 \mathrm{~cm}$ e de $20-40$ $\mathrm{cm}$, na região de projeção da copa das plantas, sendo coletada uma amostra composta para cada tratamento. Em cada planta, foram feitas duas amostragens, totalizando 16 pontos de amostragens por tratamento. $\mathrm{Na}$ amostragem foliar, foram coletadas quatro folhas por planta, uma em cada ponto cardeal, na parte mediana da copa e do último fluxo de vegetação, no período de florescimento (Silva et al., 2002). As amostras de solo e folhas foram acondicionadas de forma apropriada, identificadas e encaminhadas para laboratório credenciado para análises.

A análise estatística empregada no presente trabalho foi descritiva, sem o objetivo de comparar qual adubação promoveu melhor fertilidade e nutrição das plantas, apenas descrever os resultados encontrados. Os resultados foram apresentados com a média e o erro padrão.

\section{RESULTADOS E DISCUSSÃO}

Após cinco anos de cultivo, verificou-se que o $\mathrm{pH}$, os teores de matéria orgânica e de macronutrientes do solo aumentaram em toda a área experimental, inclusive no controle e nas entrelinhas do pomar. O aumento de $\mathrm{pH}$ do solo certamente está associado à aplicação de $1200 \mathrm{~kg} \mathrm{ha}^{-1}$ de calcário logo após o plantio das mudas (Figura 1). Contudo, era de se esperar uma redução de $\mathrm{pH}$ nas parcelas que receberam adubação mineral

Tabela 1 - Análise química do solo da área experimental, antes da implantação do pomar

\begin{tabular}{|c|c|c|c|c|c|c|}
\hline $\mathrm{pH}$ & $\mathrm{P}$ & $\mathrm{K}$ & $\mathrm{Ca}$ & $\mathrm{Mg}$ & $\mathrm{Al}$ & MO \\
\hline & \multicolumn{2}{|c|}{$\mathrm{mg} \mathrm{dm}^{-3}$} & \multicolumn{3}{|c|}{$\mathrm{cmol}_{\mathrm{c}} \mathrm{dm}^{-3}$} & dag $\mathrm{kg}^{-1}$ \\
\hline 5,40 & 4,00 & 68,00 & 0,80 & 0,60 & 0,00 & 1,10 \\
\hline
\end{tabular}


Tabela 2 - Adubação de plantio, formação e produção fornecida às plantas do tratamento MIN ao longo dos anos. SA (sulfato de amônio), SS (superfosfato simples), KCl (cloreto de potássio) e CO (composto orgânico)

\begin{tabular}{ccccc}
\hline Ano & SA (g/planta) & SS (g/planta) & KCl (g/planta) & CO (L/planta) \\
\hline Plantio (2007) & 0 & 400 & 0 & 20 \\
$1^{\circ}$ Ano (2008) & 150 & 0 & 0 & 0 \\
$2^{\circ}$ Ano (2009) & 300 & 800 & 140 & 0 \\
$3^{\circ}$ Ano (2010) & 600 & 1200 & 280 & 0 \\
$4^{\circ}$ Ano (2011) & 800 & 1600 & 400 & 0 \\
$5^{\circ}$ Ano (2012) & 1000 & 2000 & 500 & 0 \\
$6^{\circ}$ Ano (2013) & 1000 & 2000 & 500 & 0 \\
\hline
\end{tabular}

Tabela 3 - Adução de plantio, formação e produção fornecida às plantas do tratamento ORG ao longo dos anos. CO (composto orgânico), CDF (cama de frango), TE (termofosfato) e CZ (cinza de eucalipto)

\begin{tabular}{ccccc}
\hline Ano & CO (L/pl.) & CDF (L/pl) & TE (g/pl.) & CZ (g/pl.) \\
\hline Plantio (2007) & 20 & 0 & 400 & 0 \\
$1^{\circ}$ Ano (2008) & 0 & 12 & 0 & 0 \\
$2^{\circ}$ Ano (2009) & 0 & 24 & 500 & 0 \\
$3^{\circ}$ Ano (2010) & 0 & 48 & 700 & 0 \\
$4^{\circ}$ Ano (2011) & 0 & 60 & 800 & 400 \\
$5^{\circ}$ Ano (2012) & 0 & 80 & 1000 & 500 \\
$6^{\circ}$ Ano (2013) & 0 & 60 & 1000 & 500 \\
\hline
\end{tabular}

Tabela 4 - Adubação de plantio, formação e produção fornecida às plantas do tratamento ORM ao longo dos anos. CO (composto orgânico), CDF (cama de frango), TE (termofosfato), CZ (cinza), SA (sulfato de amônio), SS (superfosfato simples), $\mathrm{KCl}$ (cloreto de potássio)

\begin{tabular}{cccccccc}
\hline Ano & CO (L/pl.) & CDF (L/pl) & TE (g/pl.) & CZ (g/pl.) & SA (g/pl) & SS (g/pl.) & KCl (g/pl.) \\
\hline Plantio (2007) & 20 & 0 & 200 & 0 & 0 & 200 & 0 \\
$1^{\circ}$ Ano (2008) & 0 & 6 & 0 & 0 & 80 & 0 & 700 \\
$2^{\circ}$ Ano (2009) & 0 & 12 & 250 & 0 & 150 & 600 & 140 \\
$3^{\circ}$ Ano (2010) & 0 & 24 & 360 & 0 & 300 & 800 & 200 \\
$4^{\circ}$ Ano (2011) & 0 & 30 & 400 & 200 & 400 & 1000 & 250 \\
$5^{\circ}$ Ano (2012) & 0 & 40 & 500 & 250 & 500 & 1000 \\
$6^{\circ}$ Ano (2013) & 0 & 30 & 500 & 250 & 500 & 250 \\
\hline
\end{tabular}

nitrogenada (Pires et al., 2008) ao longo dos seis anos de cultivo, o que não ocorreu, certamente devido ao efeito tampão da matéria orgânica aportada ao solo pelas roçadas periódicas da braquiária presente nas entrelinhas do pomar.

Houve um aumento expressivo do teor de matéria orgânica do solo na camada de 0 a $20 \mathrm{~cm}$ de profundidade, em toda área experimental, inclusive nas parcelas que receberam adubação mineral e nas entrelinhas do pomar, sendo que nesta última área o único manejo adotado foi a roçada periódica da braquiária (Figura 2).
Os menores acréscimos de pH ocorreram nas parcelas que receberam adubação mineral e organomineral, o que pode ter ocorrido em função da aplicação de adubos minerais, especialmente sulfato de amônio. Em bananeiras, após dois ciclos de cultivo, a adubação nitrogenada causou decréscimos significativos nos valores de $\mathrm{pH}$ do solo, saturação por bases e teor de Mg trocável (Teixeira et al., 2001). No presente estudo, os efeitos positivos da calagem e do acúmulo de matéria orgânica sobre o solo foi parcialmente neutralizado pela aplicação de adubos 


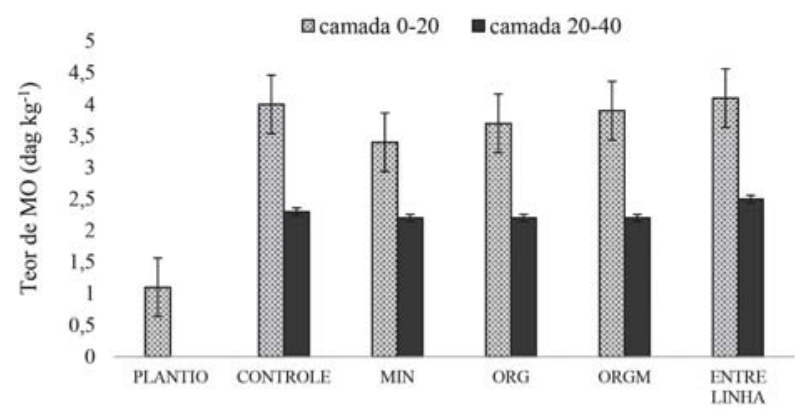

Figura 2 - Teor de matéria orgânica $\left(\mathrm{dag} \mathrm{kg}^{-1}\right)$ do solo da área experimental, no plantio (2007) e ao final do experimento (2013). Adubações: controle, mineral (MIN), orgânica (ORG) e organomineral (ORGM).

minerais. Pires et al. (2008) avaliando o efeito da adubação alternativa no solo cultivado com maracujazeiro amarelo, observaram que com a aplicação de adubos orgânicos houve um aumento do $\mathrm{pH}$ do solo em todas as profundidades, efeito este positivo para a cultura, uma vez que tal aumento promove maior disponibilidade de nutrientes. Por outro lado, o pH do solo adubado com fertilizante mineral foi menor que o adubado com adubos orgânicos. A elevação do $\mathrm{pH}$ do solo adubado com compostos orgânicos pode ser atribuída à formação de radical amina, $\mathrm{R}-\mathrm{NH}_{2}$, no processo conhecido como aminação (Tisdale \& Nelson, 1967).

Em relação ao fósforo e potássio observa-se um aumento mais expressivo na camada de 0 a $20 \mathrm{~cm}$ de profundidade, especialmente nas parcelas que receberam adubação orgânica com cama-de-frango (Figuras 3 e 4). Provavelmente isto foi devido ao fato da adubação orgânica, equivalente a mineral, ter sido calculada baseando-se na necessidade de nitrogênio da cultura e não na necessidade de fósforo e de potássio. Assim, como a cama de frango utilizada apresentava um teor relativamente bom de fósforo e potássio $(0,73 \% \mathrm{P}$ ou $1,67 \%$ de $\mathrm{P}_{2} \mathrm{O}_{5} ;, 75 \% \mathrm{~K}$ ou $3,35 \%$ de $\mathrm{K}_{2} \mathrm{O}$ ), as quantidades aplicadas desses macronutrientes foram maiores que a necessidade da cultura, havendo efeito residual das adubações feitas ao longo dos anos.

Os aumentos de fósforo e potássio, nas parcelas que receberam adubações mineral e organomineral, indicam que as quantidades de adubos minerais e orgânico aplicadas foram superiores às demandas da cultura, havendo também efeitos residuais das adubações

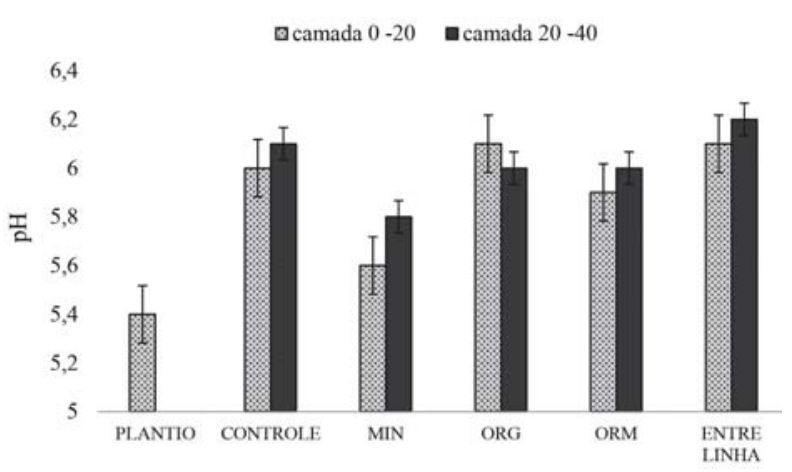

Figura 1 - Teor de pH do solo da área experimental, no plantio (2007) e ao final do experimento (2013). Adubações: controle, mineral (MIN), orgânica (ORG) e organomineral (ORM).

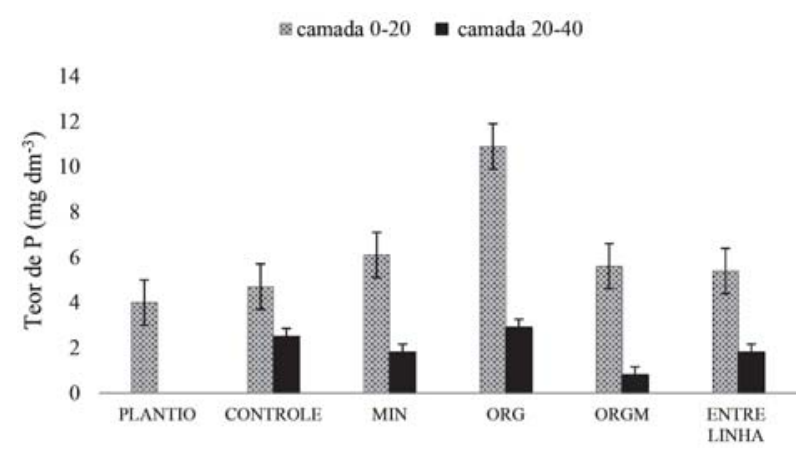

Figura 3 - Teor de $\mathrm{P}\left(\mathrm{mg} \mathrm{dm}^{-3}\right)$ do solo da área experimental, no plantio (2007) e ao final do experimento (2013). Adubações: controle, mineral (MIN), orgânica (ORG) e organomineral (ORGM).

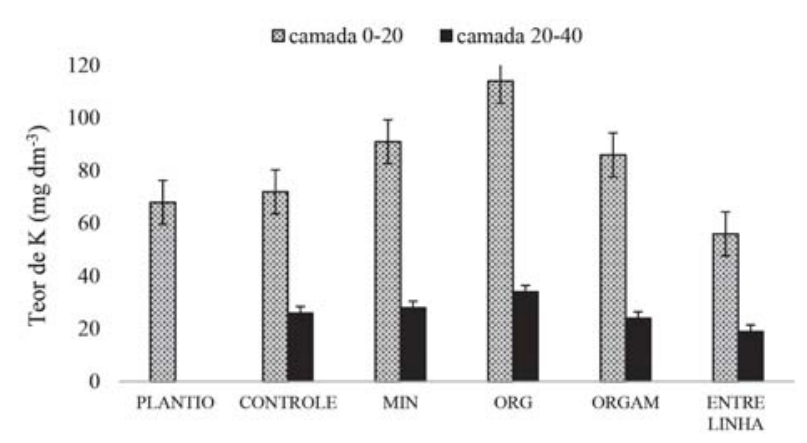

Figura 4 - Teor de K $\left(\mathrm{mg} \mathrm{dm}^{-3}\right)$ do solo da área experimental, no plantio (2007) e ao final do experimento (2013). Adubações: controle, mineral (MIN), orgânica (ORG) e organomineral (ORGAM). 
(Silva \& Fontes, 2016; Vasconcelos et al., 2017). Possivelmente estes efeitos residuais ocorreram devido a uma produção de frutos menor que a expectativa de produção considerada por ocasião do cálculo das adubações anuais. Verifica-se um ligeiro aumento de fósforo na parcela controle e nas entrelinhas do pomar, especialmente na camada de 0 a $20 \mathrm{~cm}$ de profundidade, o que pode ser atribuído à ciclagem de fósforo pela braquiária presente nas entrelinhas. O mesmo efeito era esperado para potássio, o que não ocorreu, provavelmente devido ao fato deste elemento ser facilmente lixiviado para camadas mais profundas do solo, o que não ocorreu com o fósforo, que é um elemento pouco móvel no perfil do solo.

Os incrementos relativos de Ca, na camada de 0$20 \mathrm{~cm}$, foram de 675\%, 562,5\%, 625\%, 625\% e 625\% em relação ao plantio para os tratamentos controle, adubação mineral, orgânica, organomineral e na entre linha das plantas, respectivamente. Na camada de 20$40 \mathrm{~cm}$, foram de 562,5\%, 500\%,512,5\%, 562,5\% e 267\% em relação ao plantio para os tratamentos controle, adubação mineral, orgânica, organomineral e na entre linha das plantas, respectivamente. Esses resultados são, provavelmente, devidos à calagem superficial realizada em toda área do pomar logo após o plantio das mudas (Figura 5). Em relação ao magnésio, uma vez que foi utilizado calcário dolomítico, os incrementos relativos, na camada de $0-20 \mathrm{~cm}$, foram de $283 \%$, 250\%, $283 \%$, 283\% e $266 \%$ em relação ao plantio para os tratamentos controle, adubação mineral, orgânica, organomineral e na entre linha das plantas, respectivamente. Na camada de $20-40 \mathrm{~cm}$, foram de 250\%, 250\%, 233\%, 266\% e 233\% em relação ao plantio para os tratamentos controle, adubação mineral, orgânica, organomineral e na entre linha das plantas, respectivamente (Figura 6). O incremento de 283\% no teor de magnésio, na camada de $0-20 \mathrm{~cm}$, na parcela que recebeu adubação orgânica se deve ao fato da cama de frango apresentar 0,99\% de Mg. Uma das grandes vantagens da utilização de adubos orgânicos nas adubações de plantas é que estes, além de fornecerem NPK, fornecem também vários outros nutrientes essenciais às plantas.

Em cultivo orgânico de mangueiras ‘Tommy Atkins’, conduzidas com irrigação, no semi-árido nordestino, Silva et al. (2013) determinaram que o uso de compostos orgânicos foi eficiente no aumento dos teores de matéria orgânica do solo e $\mathrm{pH}$, mas este em pequena intensidade e apenas na profundidade de 20 - $40 \mathrm{~cm}$. O suprimento de nutrientes às fruteiras em sistemas orgânicos pode ser feito através de diferentes práticas e adubos. Os adubos utilizados podem ser obtidos na própria unidade de produção (livres de contaminantes) - como compostos orgânicos, vermicomposto ou estercos animais - ou podem ser adquiridos fora da unidade produtiva, desde que autorizados pela certificadora. A composição dos estercos varia de acordo com a espécie animal, a cama utilizada, a alimentação do animal e os cuidados na sua manipulação (Borges et al., 2003).

O teor de Al no solo da área experimental não se alterou, permanecendo em $0,0 \mathrm{cmol}_{\mathrm{c}} \cdot \mathrm{dm}^{-3}$ (Tabela 1 ).

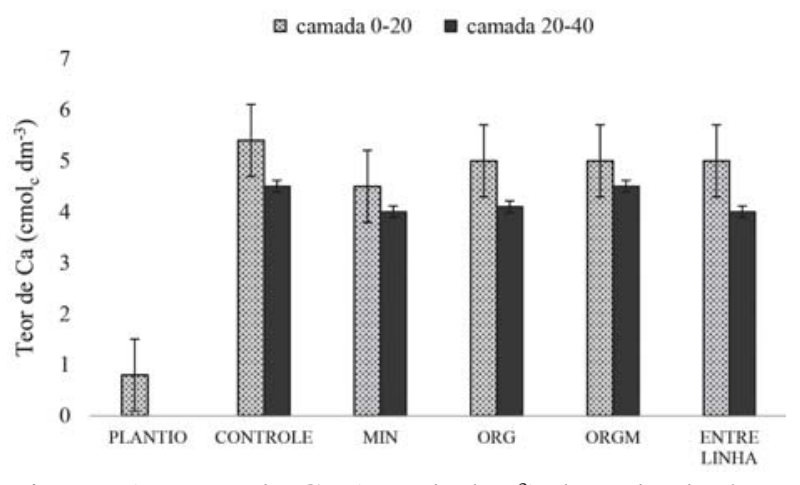

Figura 5 - Teor de Ca $\left(\mathrm{cmol}_{\mathrm{c}} \mathrm{dm}^{-3}\right)$ do solo da área experimental, no plantio (2007) e ao final do experimento (2013). Adubações: controle, mineral (MIN), orgânica (ORG) e organomineral (ORGM).

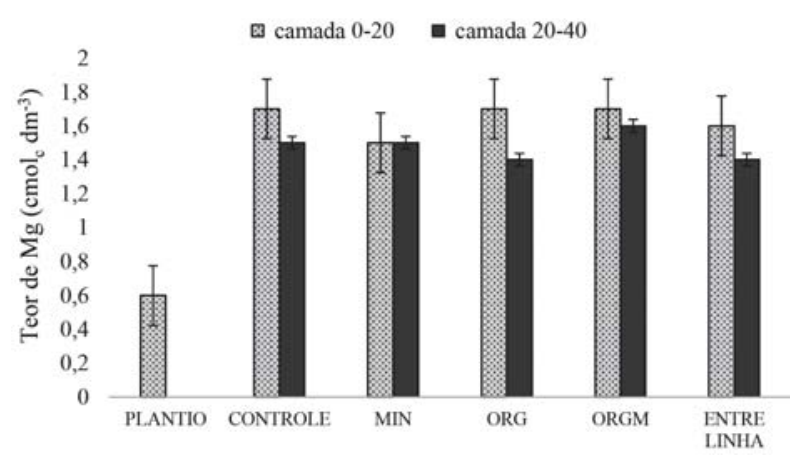

Figura 6 - Teor de $\mathrm{Mg}\left(\mathrm{cmol}_{\mathrm{c}} \mathrm{dm}^{-3}\right)$ do solo da área experimental, no plantio (2007) e ao final do experimento (2013). Adubações: controle, mineral (MIN), orgânica (ORG) e organomineral (ORGM). 
Além do benefício da calagem, o aumento nos teores de nutrientes, de $\mathrm{pH}$ e de matéria orgânica no tratamento controle e nas entrelinhas do pomar pode estar associado ao processo de ciclagem de nutrientes, uma vez que o pomar era roçado três vezes ao ano e toda biomassa roçada era deixada sobre o solo. Resíduos culturais na superfície do solo constituem importante reserva de nutrientes (Rosolem et al., 2003). Porém, para que a cultura seja beneficiada, deve haver sincronia entre o nutriente liberado pelo resíduo da planta de cobertura e a demanda da cultura de interesse comercial (Braz et al., 2004). A espécie dominante na área experimental era o capim Brachiaria brizantha, que apresentou uma elevada capacidade de produção de biomassa. Como a área não estava aberta ao pastejo de animais, toda a biomassa produzida foi adicionada solo.

Em relação aos teores de $\mathrm{P}$ e K no solo os maiores aumentos nos níveis destes nutrientes ocorreram nas parcelas adubadas, especialmente nas parcelas que receberam adubação orgânica. Este aumento de P e $\mathrm{K}$ ocorreu provavelmente devido aos efeitos residuais das adubações orgânicas realizadas ao longo dos anos. Santos et al. (2010) avaliando o efeito residual da adubação orgânica com esterco bovino sobre o acúmulo de nutrientes no solo e a produtividade do milho, encontraram maior efeito residual nas parcelas adubadas com esterco bovino. Além disso, ao longo de dois anos de estudo, os teores de P, K, Ca e Mg no solo foram mais elevados nas parcelas que receberam esterco como adubo. Como o cálculo das adubações orgânicas foi baseado na necessidade da cultura por $\mathrm{N}$ adicionou-se, de modo geral, maiores quantidades dos outros nutrientes que as exigidas pela cultura. $\mathrm{O}$ aumento nos teores de $\mathrm{K}$, e, principalmente, de $\mathrm{P}$, em solos que recebem adubações orgânicas frequentes é bastante comum. A aplicação de esterco de caprino contribuiu para melhorar as características do solo, principalmente, a fertilidade, obtendo aumentos dos teores de $\mathrm{P}, \mathrm{K}$ e $\mathrm{Mg}$, comparativamente ao solo com ausência de adubo orgânico (Melo et al., 2009).

Plantas que receberam adubação organomineral apresentaram teores foliares de nutrientes ligeiramente superiores às demais, indicando uma boa eficiência da adubação organomineral na nutrição das plantas (Figura 7). Para a mangueira, as faixas de macro e micronutrientes consideradas adequadas nos tecidos foliares são: 12 a $14 \mathrm{~g} \mathrm{~kg}^{-1}$ para N; 0,8 a 1,6 g kg-1 para P; 5 a 10 g kg-1 $^{-1}$ para K; 20 a 35 g kg $^{-1}$ para Ca; 2,5 a
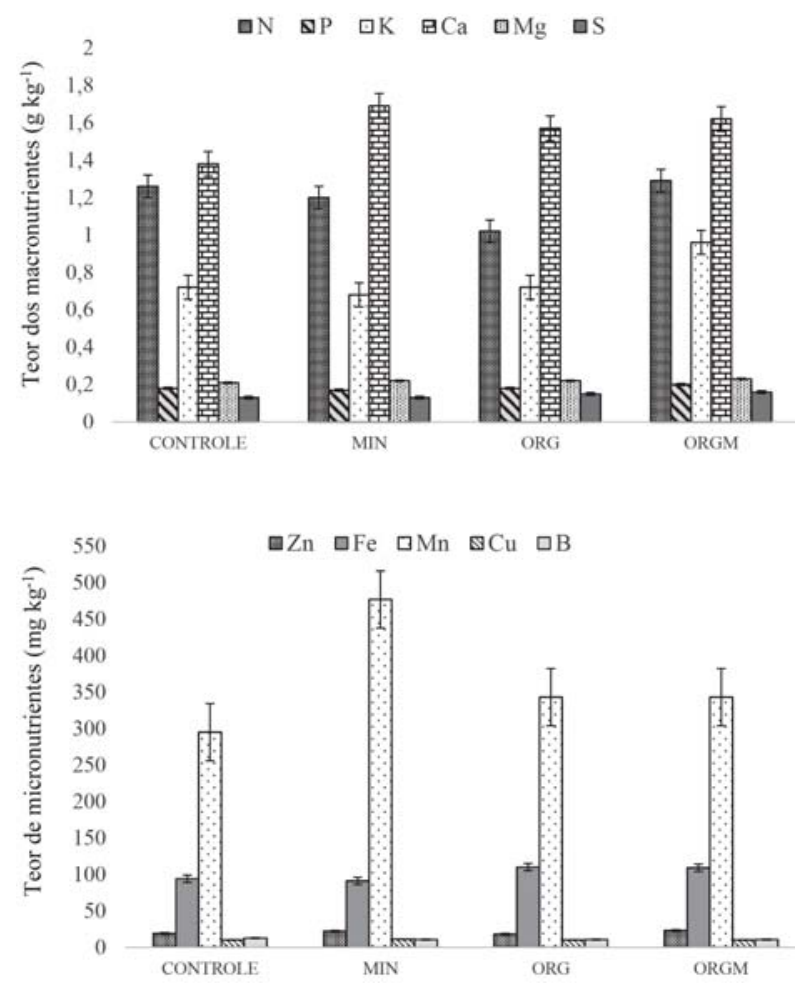

Figura 7 - Teor foliar de macro e micronutrientes (N, $\mathrm{P}, \mathrm{K}, \mathrm{Ca}, \mathrm{Mg}, \mathrm{S}, \mathrm{Zn}, \mathrm{Fe}, \mathrm{Mn}, \mathrm{Cu}, \mathrm{B})$ em mangueiras 'Ubá', ao final do experimento (2013). Adubações: controle, mineral (MIN), orgânica (ORG) e organomineral (ORGM).

5,0 $\mathrm{g} \mathrm{kg}^{-1}$ para Mg; 0,8 a 1,8 $\mathrm{g} \mathrm{kg}^{-1}$ para S; 50 a 100 $\mathrm{mg} \mathrm{kg}^{-1}$ para B; 10 a $50 \mathrm{mg} \mathrm{kg}^{-1}$ para $\mathrm{Cu} ; 50$ a $200 \mathrm{mg}$ $\mathrm{kg}^{-1}$ para Fe; 50 a $100 \mathrm{mg} \mathrm{kg}^{-1}$ para Mn e 20 a $40 \mathrm{mg}$ $\mathrm{kg}^{-1}$ para Zn (Silva et al., 2002).

Plantas que receberam adubação orgânica apresentaram os mais baixos teores de $\mathrm{N}$ foliar $(10,2$ $\mathrm{g} / \mathrm{kg}$ ), ficando um pouco abaixo da faixa indicada para a cultura, o que pode ser atribuído ao fato da adubação orgânica ter sido calculada baseada na necessidade da cultura em nitrogênio, ou seja, foi adicionada apenas a quantidade de $\mathrm{N}$ exigida pela cultura, e também à liberação mais lenta dos nutrientes presentes nos adubos orgânicos comparados aos adubos minerais (Silva et al., 2014). Todas as plantas apresentaram teores foliares de $\mathrm{P}$ acima da faixa recomendada, teores de $\mathrm{K}$ dentro da faixa e teores de Ca, Mg e S abaixo da faixa indicada para a cultura. Plantas do tratamento controle apresentaram, de modo geral, teores foliares de nutrientes 
próximos de plantas adubadas certamente devido à baixa exportação de nutrientes pelas colheitas de frutos.

Os teores foliares de nutrientes avaliados na última safra não variaram muito entre as plantas que receberam os diferentes tipos de adubação, apesar da detecção de diferentes teores de nutrientes no solo. Os teores foliares de N, K e Ca obtidos no presente trabalho são inferiores aos obtidos por Silva et al. (2013), sendo observado efeito contrário em relação ao teor foliar de P. Atribui-se à ausência de irrigação os menores teores nutricionais obtidos nas condições desse experimento, uma vez que no trabalho de Silva et al. (2013) a irrigação era realizada diariamente.

\section{CONCLUSÕES}

Adubações orgânicas realizadas com cama de frango, ao longo de seis anos de cultivo, resultam em maiores efeitos residuais de fósforo, potássio e magnésio no solo que adubações minerais e organominerais.

O manejo de Brachiaria brizantha, presente nas entrelinhas do pomar, através de roçadas periódicas, resulta em um aumento expressivo no teor de matéria orgânica do solo, além de propiciar a ciclagem de nutrientes.

A adubação organomineral proporciona uma nutrição mais equilibrada das plantas.

\section{LITERATURACITADA}

BORGES, A.L.; TRINDADE, A.V.; SOUZA, L.S. et al. Cultivo orgânico de fruteiras tropicais: manejo do solo e da cultura. Circular técnica, 64. Cruz das Almas: Embrapa Mandioca e Fruticultura, 2003. 12p.

BRAZ, A.J.B.P.; SILVEIRA, P.M.; KLIEMANN, H.J. et al. Acumulação de nutrientes em folhas de milheto e dos capins braquiária e mombaça.

Pesquisa Agropecuária Tropical, v.34, p.83-87, 2004.

IBGE - INSTITUTO BRASILEIRO DE GEOGRAFIA

E ESTATÍSTICA. Séries Estatísticas. 2010.

Disponível em: http://seriesestatisticas.ibge.gov.br/ . Acesso em: 08/02/2013.

LANA, R.M.Q.; ASSIS, D.F.; SILVA, A.A. et al. Alterações na produtividade e composição nutricional de uma pastagem após segundo ano de aplicação de diferentes doses de cama de frango.

Bioscience Journal, v.26, n.2, p.249-256, 2010.
MAPA - MINISTÉRIO DAAGRICULTURA, PECUÁRIA E ABASTECIMENTO. Estatísticas. 2012. Disponível em: http://

www.agricultura.gov.br/vegetal/estatisticas. Acesso em: 08/02/2012.

MELO, R.F.; BRITO, L.T.L.; PEREIRA, L.A. et al. Avaliação do uso de adubo orgânico nas culturas de milho e feijão caupi em barragem subterrânea.

Revista Brasileira de Agroecologia, v.4, n.2, p.1264-1267, 2009.

PACHECO, A.L.V.; BORGES, K.S.; VIEIRA, G. et al. Qualidade da manga 'Ubá' orgânica e convencional ofertada a uma agroindústria da Zona da Mata de Minas Gerais. Revista

Brasileira de Agropecuária

Sustentável, v.5, n.1, p.130-136, 2015.

PIRES, A.A.; MONNERAT, P.H.; MARCIANO, C.R. et al. Alternative manuring of the yellow passion fruit plant: effects on chemical and physical characteristics of the soil. Revista Brasileira de Ciência do Solo, v.32, n.5, p.1997-2005, 2008.

QUAGGIO, J.A.; RAIJ, B.V.; PIZA JUNIOR, C.T. Frutíferas. In: RAIJ, B.V.; CANTARELLA, H.; QUAGGIO, J.A. et al. (Eds) Boletim Técnico 100 - Recomendações de adubação e calagem para o estado de São Paulo. Instituto Agronômico, Fundação IAC. Campinas, SP. p.121153.1997.

RAMOS, A.M.; FREITAS, G.B.; NEVES, E.G.F. et al. Manga “Ubá” orgânica - Boas práticas agrícolas para produção destinada à agroindústria. Departamento de Tecnologia de Alimentos, UFV, Viçosa, MG. 2009. 75p.

ROSOLEM, C.A.; CALONEGO, J.C.; FOLONI, J.S.S. Lixiviação de potássio da palha de espécies de cobertura de solo de acordo com a quantidade de chuva aplicada. Revista Brasileira de Ciência do Solo, v.27, p.355-362, 2003.

SANTOS, A.F.; MENEZES, R.S.C.; FRAGA, V.S. et al. Efeito residual da adubação orgânica sobre a produtividade de milho em sistema agroflorestal.

Revista Brasileira de Engenharia Agrícola e Ambiental, v.14, n.12, p.12671272, 2010. 
SANTOS, H.G.; JACOMINE, P.K.T.; ANJOS, L.H.C. et al. Sistema brasileiro de classificação de solos. 3.ed. Brasília: Embrapa, 2013. 353p.

SILVA, D.J.; QUAGGIO, J.A.; PINTO, P.A.C. et al. Nutrição e adubação. In: GENÚ, P.J.C.; PINTO, A.C.Q. (Eds) A cultura da Mangueira. Brasília: Embrapa Informação Tecnológica, p.192221, 2002.

SILVA, D.J.; MOUCO, M.A.C.; GAVA, C.A.T. et al. Composto orgânico em mangueiras (Mangifera indica L.) cultivadas com semiárido do nordeste brasileiro. Revista Brasileira de

Fruticultura, v.35, n.3, p.875-882, 2013.

SILVA, H.R.F; FONTES, P.C.R. Adubação potássica e seu efeito residual sobre a produção e a qualidade de tubérculos de batata. Pesquisa Agropecuária Brasileira, v.51, n.7, p.842848, 2016.
SILVA, V.B.; SILVA, A.P.; DIAS, B.O. et al. Decomposition and mineralization of $\mathrm{N}, \mathrm{P}$ and $\mathrm{K}$ of cattle manure and poultry litter isolated or mixed. Revista Brasileira de Ciência do Solo, v.38, n.5, p.1537-1546. 2014.

TEIXEIRA, L.A.J.; NATALE, W.; RUGGIERO, C. Alterações em alguns atributos químicos do solo decorrentes da irrigação e adubação nitrogenada e potássica em bananeira após dois ciclos de cultivo. Revista Brasileira de

Fruticultura, v.23, n.3, p.684-689, 2001.

TISDALE, S.L.; NELSON, W.L. Soil fertility and fertilizers. 2.ed. New York, Macmillan, 1967. 694p.

VASCONCELOS, U.A.A.; COSTA, C.C.; OLIVEIRA, M.N. et al. Efeito residual do esterco ovino no cultivo da alface em diferentes espaçamentos. Revista Verde de Agroecologia e Desenvolvimento Sustentável, v.12, n.3, p.508-511, 2017.

Recebido para publicação em 5/11/2017 e aprovado em 9/3/2018. 